University of Nebraska - Lincoln

DigitalCommons@University of Nebraska - Lincoln

May 1997

\title{
Nickel doping of boron-carbon alloy films and corresponding Fermi level shifts
}

\author{
Seong-Don Hwang \\ University of Nebraska-Lincoln \\ N. Remmes \\ University of Nebraska-Lincoln \\ Peter A. Dowben \\ University of Nebraska-Lincoln, pdowben@unl.edu \\ D.N. Mcllroy \\ University of Idaho
}

Follow this and additional works at: https://digitalcommons.unl.edu/physicsdowben

Part of the Physics Commons

Hwang, Seong-Don; Remmes, N.; Dowben, Peter A.; and Mcllroy, D.N., "Nickel doping of boron-carbon alloy films and corresponding Fermi level shifts" (1997). Peter Dowben Publications. 121.

https://digitalcommons.unl.edu/physicsdowben/121

This Article is brought to you for free and open access by the Research Papers in Physics and Astronomy at DigitalCommons@University of Nebraska - Lincoln. It has been accepted for inclusion in Peter Dowben Publications by an authorized administrator of DigitalCommons@University of Nebraska - Lincoln. 


\title{
Nickel doping of boron-carbon alloy films and corresponding Fermi level shifts
}

\author{
Seong-Don Hwang, N. Remmes, and P. A. Dowben \\ Department of Physics and Center for Materials Research and Analysis, \\ University of Nebraska-Lincoln, Lincoln, Nebraska 68588-0111 \\ D. N. Mcllroy ${ }^{a)}$ \\ Department of Physics, University of Idaho, Moscow, Idaho 83844-0903
}

(Received 20 October 1996; accepted 3 March 1997)

\begin{abstract}
We have grown nickel doped boron-carbon alloy films by the technique of plasma enhanced chemical vapor deposition. The source gas closo-1,2-dicarbadodecaborane (orthocarborane) was used to grow the boron-carbon alloy, while nickelocene $\left[\mathrm{Ni}\left(\mathrm{C}_{5} \mathrm{H}_{5}\right)_{2}\right]$ was used as the dopant source for nickel. With sufficient levels of Ni doping, diodes with characteristic tunnel diode behavior can be fabricated. The doping of nickel transformed a $\mathrm{B}_{5} \mathrm{C} p$-type material, relative to lightly doped $n$-type silicon, to a strongly $n$-type material. In order to gain insight into the shift of the Fermi level of the Ni-doped material, we have examined the changes in the electronic structure of sodium doped films of the precursor molecule orthocarborane which has an icosahedral structure similar to that of boron-carbon materials. The establishment of unoccupied states at the Fermi level with Na doping of the orthocarborane films is consistent with the transformation of the $p$-type $\mathrm{B}_{5} \mathrm{C}$ to an $n$-type material with Ni doping. (C) 1997 American Vacuum Society. [S0734-2101(97)08003-2]
\end{abstract}

\section{INTRODUCTION}

The need for semiconductor devices which can operate at high temperatures and in harsh environments has been a goal for many decades. Boron-rich solids are refractory materials with melting temperatures of $2400{ }^{\circ} \mathrm{C}$ and therefore are excellent candidates for device applications which require electronic and structural stability at elevated temperatures $\left(>300{ }^{\circ} \mathrm{C}\right)$. In addition, they are highly corrosion resistant making them an ideal material for applications in corrosive environments. The development of thin film deposition techniques for boron-rich boron carbide, and boron-carbon alloys would greatly accelerate the realization of boron based high temperature devices.

Through the decomposition of cluster borane molecules by plasma-enhanced ${ }^{1-6}$ and synchrotron radiation-induced ${ }^{1,7}$ chemical vapor deposition, heterojunction devices of boron and boron-carbon alloy films have been successfully fabricated. These techniques have not only been used to construct simple diodes, but have also successfully yielded field effect transistors. ${ }^{2}$ These devices were constructed with undoped boron-carbon alloy thin films. In order to construct true homojunction devices, an $n$-type boron-carbon alloy is necessary. This is only possible through doping.

The introduction of metal dopants into boron-carbon alloy films is not a trivial process. The traditional silicon dopants-boron and phosphorus-substitutionally alloy in this material and change the band gap without necessarily changing the conduction properties. ${ }^{4}$ Initial attempts to dope molecular films of the precursor cluster molecule closo-1,2dicarbadodecaborane $\left(\mathrm{C}_{2} \mathrm{~B}_{10} \mathrm{H}_{12}\right)$, otherwise known as orthocarborane, with the common dopant mercury were

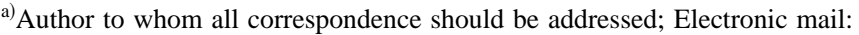
dmcilroy@uidaho.edu unsuccessful. ${ }^{8}$ Mercury segregates to the molecular filmsubstrate interface and is indicative of the weak interaction between $\mathrm{Hg}$ and orthocarborane. The possibility of doping boron-carbon alloy films with $\mathrm{Hg}$ cannot be excluded based on these results. While initially disappointing, subsequent attempts to dope molecular films of orthocarborane with sodium did prove to be successful. ${ }^{8-10}$ This work, nonetheless, did suggest that doping of this material may be a complex process. This is particularly true since the suitability of orthocarborane $\left(\mathrm{C}_{2} \mathrm{~B}_{10} \mathrm{H}_{12}\right)$ for the chemical vapor deposition of a $\mathrm{B}_{5} \mathrm{C}$ films has been established ${ }^{1-3,7}$ and because this molecule is very similar to the "building block" of boron carbide, which consists of a network of icosahedra.

Nickel, however, is a very promising dopant for the boron-rich solids. Nickel is a common component in the boron carbide superconductors ${ }^{11-15}$ and the reactions of nickel with boron phosphide have been investigated. ${ }^{16,17}$ The inclusion of nickel in other boron-rich solids is also well established. A molecular nickel carborane complex (nickelocene) has been synthesized by inorganic chemists. ${ }^{18-21}$ Nickelocene, $\mathrm{Ni}\left(\mathrm{C}_{5} \mathrm{H}_{5}\right)_{2}$, has been shown to be an excellent source compound for the deposition of nickel containing thin films. ${ }^{22-24}$ It is volatile and far less toxic than nickeltetracarbonyl, though a number of other nickel containing organometallic compounds may be suitable. ${ }^{25,26}$ Since both orthocarborane and nickelocene are easily sublimed from the solid, the introduction of suitable mixtures into the plasma reactor can be readily accomplished. The doping of nickel is seen to transform the plasma enhanced chemical vapor deposition (PECVD) $\mathrm{B}_{5} \mathrm{C}$ material to a $n$-type material. ${ }^{3}$ Both $n-n$ heterojunction diodes and $n-p$ heterojunction diodes have been constructed using $n$ - and $p$-type $\operatorname{Si}(111)$ substrates, respectively, and, with sufficient doping, diodes with 

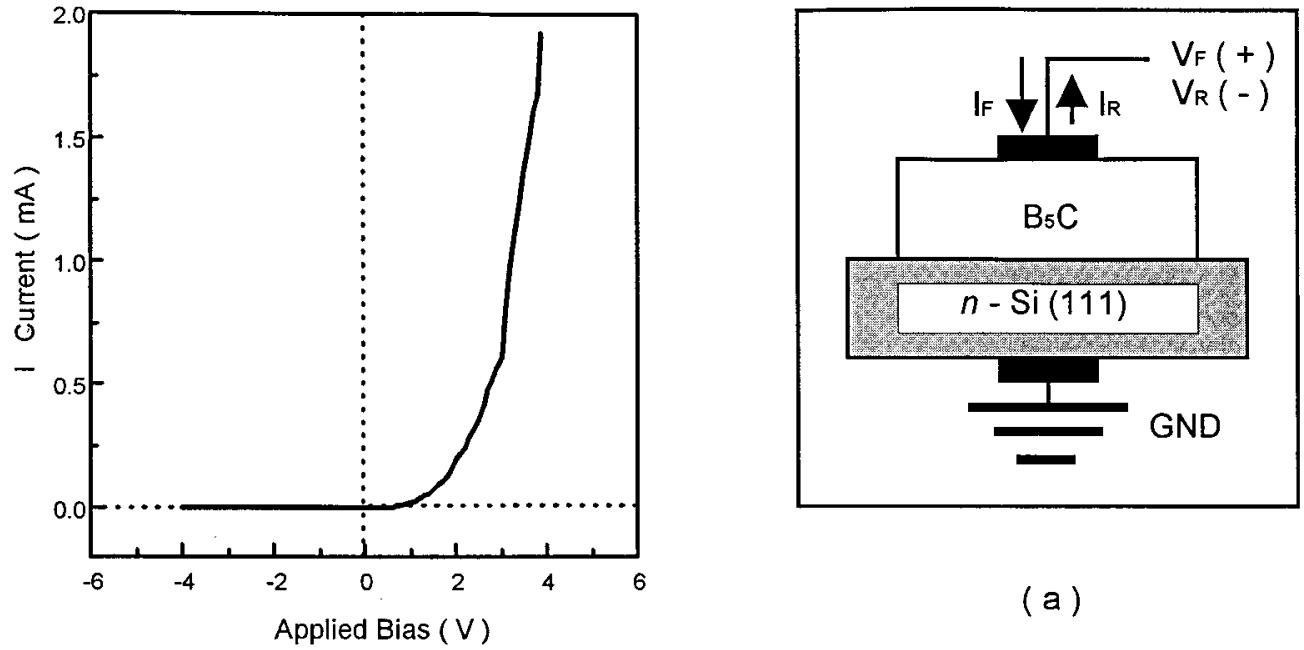

(a)
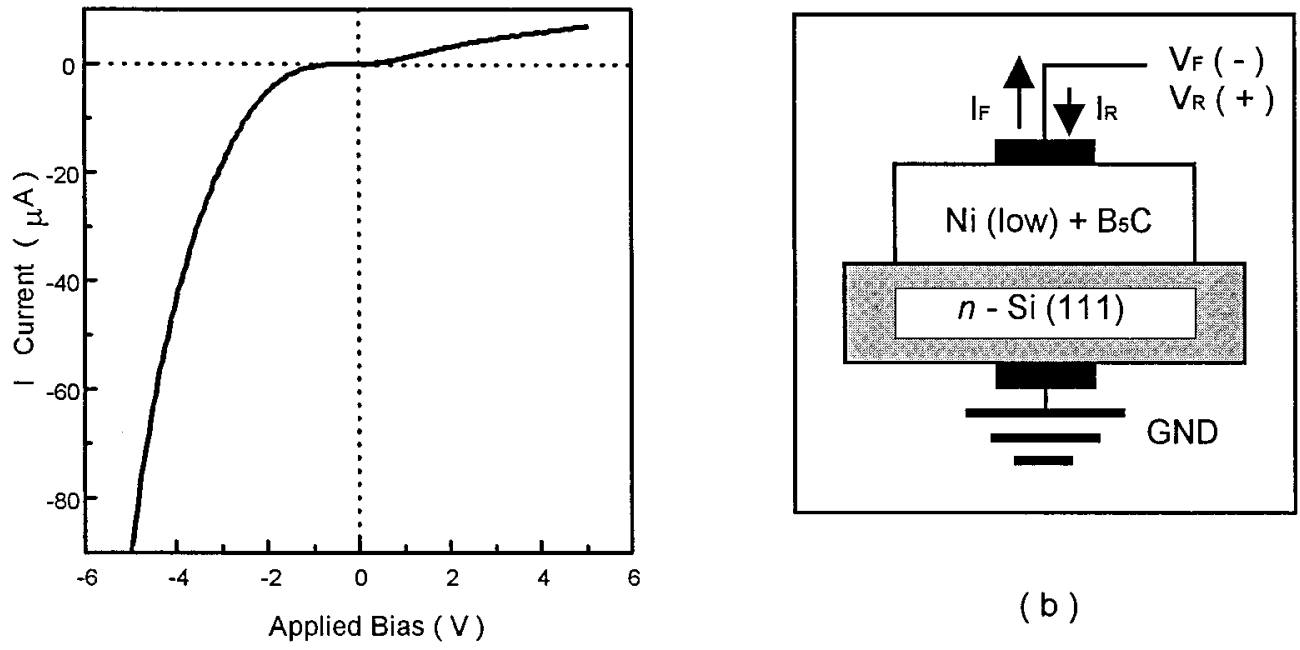

(b)
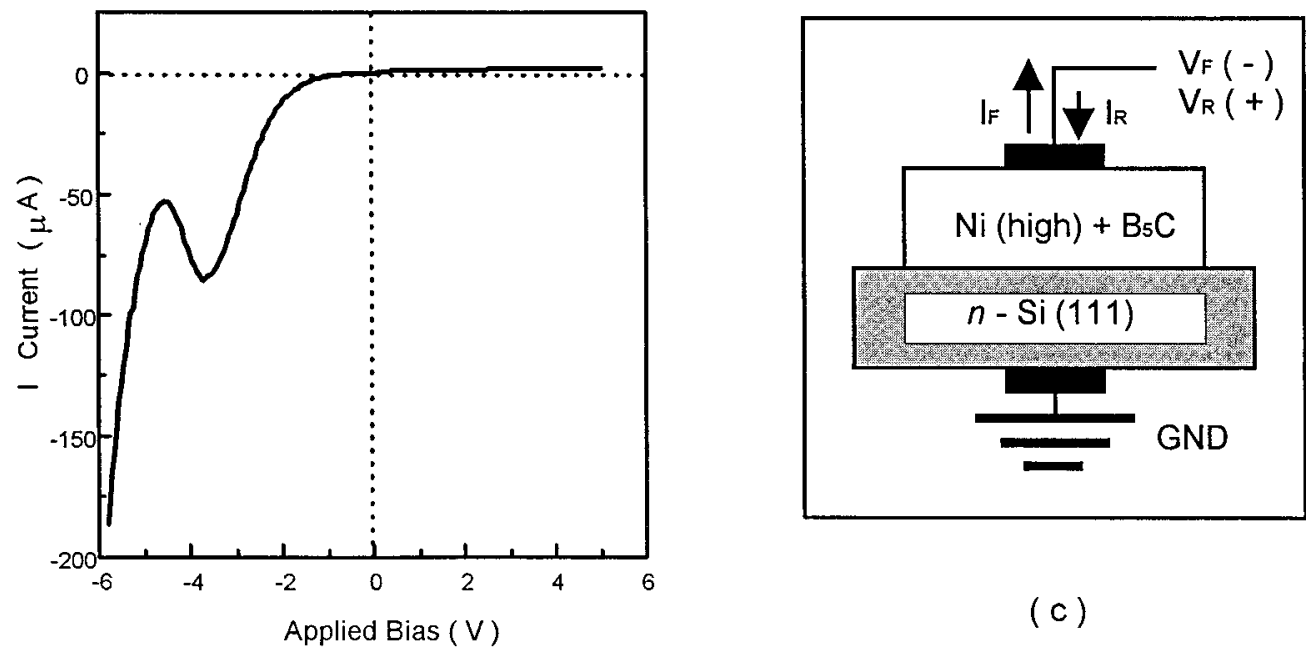

(c)

FIG. 1. The $I-V$ characteristics and the corresponding schematic diagrams of the diodes (a) $\mathrm{B}_{5} \mathrm{C} / n$ - $\mathrm{Si}(111)$, (b) lightly Ni-doped $\mathrm{B}_{5} \mathrm{C}$ on $n$-Si(111), and (c) heavily $\mathrm{Ni}$-doped $\mathrm{B}_{5} \mathrm{C}$ on $n$ - $\mathrm{Si}(111)$. The shift in polarity of the diode demonstrates the relative $n$-type behavior following nickel doping and the characteristic behavior with sufficiently high levels of nickel doping. $I_{F}$ and $I_{R}$ are used to designate forward and reverse direction of current, respectively.

the characteristics of a tunnel diode have been fabricated. ${ }^{3}$

In this article we compare the electronic structure of $\mathrm{Ni}$ doped boron-carbon alloy films grown by PECVD with Nadoped films of the icosahedral molecular precursor orthocarborane used in the PECVD process for growing boron- carbon alloys. In spite of the large differences between these two systems, similarities do exist. Molecular models of semiconductor materials may be useful towards finding new routes for the fabrication and development of boron-carbon materials. 


\section{GROWTH AND EXPERIMENTAL PROCEDURE}

\section{A. Doped and undoped boron-carbon alloy thin films}

The $p$ - $n$ and $n-p$ heterojunctions were formed by depositing boron-carbon alloy thin films on $n$-type $\mathrm{Si}(111)$ substrates following procedures described in detail elsewhere. ${ }^{1,4-6}$ Deposition of the films was performed in a custom designed parallel plate $13.56 \mathrm{MHz}$ rf PECVD reactor used in previous studies. ${ }^{4-6}$ The silicon substrates were doped to $7 \times 10^{14} / \mathrm{cm}^{3}$. The source molecule closo-1,2dicarbadodecarborane (orthocarborane) was used as the source compound for growing the boron-carbon alloy films, while nickelocene $\left[\mathrm{Ni}\left(\mathrm{C}_{5} \mathrm{H}_{5}\right)_{2}\right]$ was used as the nickel source for doping. Nickelocene was simultaneously introduced into the plasma reactor with orthocarborane (closo-1,2dicarbadodecaborane $\left.\left[\mathrm{C}_{2} \mathrm{~B}_{10} \mathrm{H}_{12}\right)\right]$. The boron-carbon alloy films grown by this method have small crystal grains with icosahedral structure, ${ }^{1}$ similar to the boron-rich and boron carbides.

The contacts used to measure the diode characteristics of the devices were made by sputtering gold pads onto the boron-carbon films and the backside of the $\mathrm{Si}$ substrates. Wire contacts were attached to the gold pads with silver paste. This resulted in good ohmic contacts and therefore eliminated possible contributions from the contacts to the $I-V$ curves.

\section{B. Na-doped orthocarborane matrix films}

Orthocarborane adsorbs associatively on $\mathrm{Cu}(100)$ at low temperatures $(\sim 180 \mathrm{~K})$ and molecularly desorbs at approximately $450 \mathrm{~K} \cdot{ }^{27}$ As with other carborane cage molecules, ${ }^{27}$ orthocarborane bonds to the $\mathrm{Cu}(100)$ surface with the carbon atoms in the cage, but lacks any apparent preferential orientation for coverages exceeding the first monolayer. ${ }^{27}$ While a $\mathrm{Cu}$ substrate was used in this study, we have found that any number of substrates, for instance $\mathrm{Si}$, are equally suitable and therefore the choice of $\mathrm{Cu}$ was strictly one of convenience.

Sample preparation and spectroscopic studies of the doped molecular films of orthocarborane were performed in two ultrahigh vacuum (UHV) chambers, both with base pressures of $8 \times 10^{-11}$ Torr. Film growth and substrate preparation have been described in detail elsewhere. ${ }^{8,9}$ A SAES Na getter was used to dope the orthocarborane films. For the inverse photoemission studies, a Geiger-Müller detector with a $\mathrm{SrF}_{2}$ window with a pass energy of $9.5 \mathrm{eV}$ was used in conjunction with an Erdman-Zipf electron gun. All the inverse photoemission spectra were collected with the electron gun at normal incidence and the detector positioned at $35^{\circ}$ off the surface normal. The acquisition of the photoemission spectra was undertaken with a large hemispherical electron energy analyzer and a helium lamp using the He I emission line. ${ }^{10}$ The Fermi level was established from the clean, well ordered, $\mathrm{Cu}(100)$ substrate.

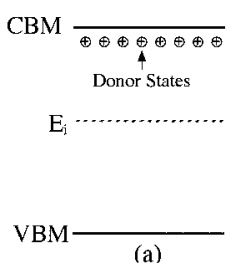

(a)

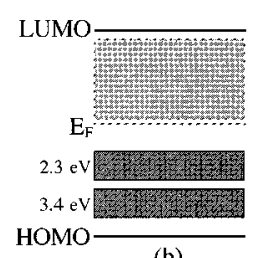

(b)

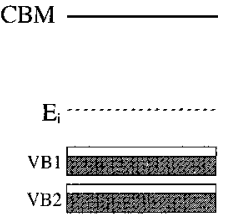

(c)
FIG. 2. Schematic energy band representations of (a) donor states in the band gap of a semiconductor, (b) the occupied and unoccupied Na-induced states in the HOMO-LUMO gap of the Na-doped orthocarborane molecular matrix film, (c) the theoretically predicted electronic structure of $\beta$-rhombohedral boron (see Ref. 43). $E_{i}$ represents the position of the chemical potential in the gap for the intrinsic semiconductor materials.

\section{RESULTS AND DISCUSSION}

\section{A. Ni-doped boron-carbon alloys}

The inclusion of $\mathrm{Ni}$ into the boron-carbon alloy films with the introduction of nickelocene into the plasma reactor has been verified with Auger electron spectroscopy (AES). The signature of Ni in the Auger spectra suggests that the Ni uptake is large and that these films are highly doped $(\gg 1$ $\left.\times 10^{21}\right)$. The $I-V$ curves of two diodes constructed with a $\mathrm{Ni}$-doped boron-carbon alloy film grown on $n$-type $\mathrm{Si}(111)$ are displayed in panels (b) and (c) in Fig. 1. The diode constructed with a "low" level of $\mathrm{Ni}$ doping corresponded to a nickelocene to orthocarborane partial pressure $<0.1$ during deposition. The "high" doping corresponded to a relative partial pressure ratio $\approx 9$, respectively.

With the inclusion of $\mathrm{Ni}$, the boron-carbon alloy films, which are normally $p$-type relative to $n$-type silicon, evolve into $n$-type materials. This is evident from the device characteristics of the diode shown in Fig. 1(b), as compared to the diode constructed with undoped boron-carbon alloy films [Fig. 1(a)]. This results in the formation of a rectifying diode with reverse bias. Thus, the nickel doped boroncarbon alloy films appear $n$-type relative to the lightly doped $n$-type silicon substrate. This is consistent with the fabrication of $n-p$ heterojunction diodes on $p$-type silicon with $\mathrm{Ni}$-doped boron-carbon alloy films.

At high doping levels of iron, the normal $p$-type behavior of $\beta$-rhombohedral boron is also seen to change to $n$-type. ${ }^{28,29}$ This change is postulated to occur when six electrons per unit cell are donated from interstitial iron atoms to the boron icosahedral network. ${ }^{30}$ This behavior is similar to what is observed in this work for nickel doping. Not all types of dopants lead to this shift from $p$-type to $n$-type. Unlike $\mathrm{Ni}$ and $\mathrm{Fe}$ doping, Mn doping leaves $\beta$-rhombohedral boron p-type. ${ }^{28}$

With the higher nickel doping, a negative differential resistance, or a valley in the current, occurs in the effective forward bias direction for diodes formed on $n$-type silicon and $p$-type $\mathrm{Si}$, as seen in Fig. 1(c). This behavior is characteristic of a tunnel diode ${ }^{31-39}$ and is consistent with degenerative doping and the introduction of donor states below the conduction band minimum. A schematic of the energy band representation is displayed in Fig. 2(a). Certainly at the higher doping levels, sufficient quantities of nickel are incor- 


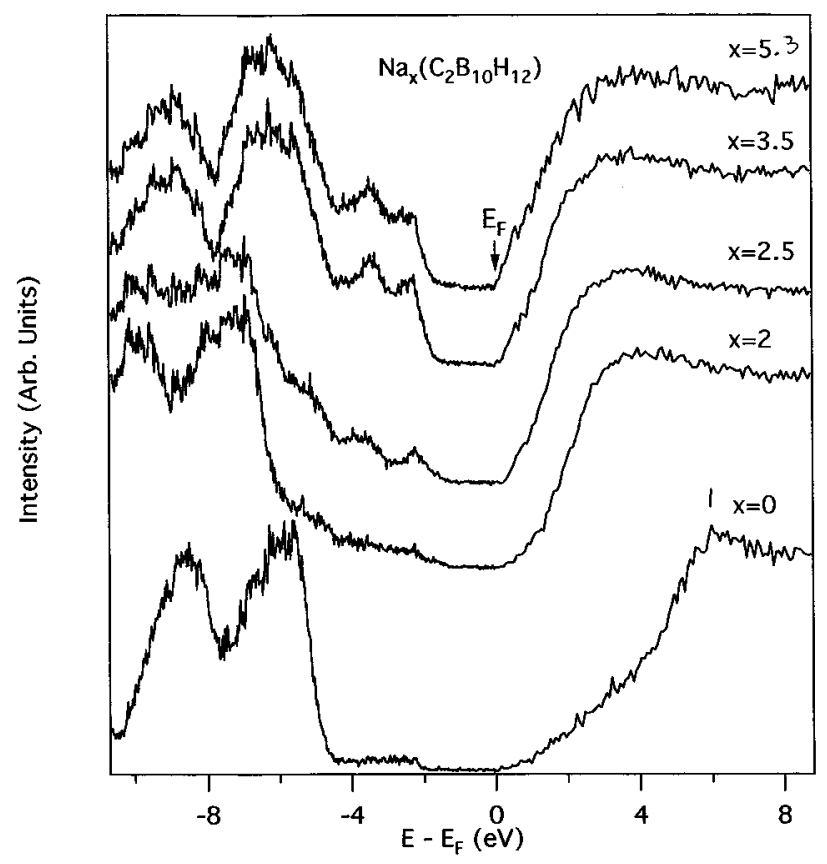

FIG. 3. Normal emission photoemission and normal incidence inverse photoemission spectra of orthocarborane on $\mathrm{Cu}(100)$ as a function of sodium doping. The photoemission spectra were acquired with a photon energy of $21.2 \mathrm{eV}$.

porated into the boron-carbon alloy during film growth to achieve a degenerative level of doping.

\section{B. Na-doped molecular matrix films of orthocarborane}

In Fig. 3 we present a series of inverse photoemission electron spectroscopy (IPES) and photoemission electron spectroscopy (PES) spectra of orthocarborane films on $\mathrm{Cu}(100)$ as a function of sodium doping. For the undoped icosahedral film, the lowest unoccupied molecular orbital (LUMO) is at an energy approximately $4.25 \mathrm{eV}$ above the Fermi level. The highest occupied molecular orbital (HOMO) is readily apparent in the photoemission spectra at a binding energy of $5.2 \pm 0.2 \mathrm{eV}$ below the Fermi level. ${ }^{10}$ At a $\mathrm{Na}$ concentration of approximately $x=2$ $\left[\mathrm{Na}_{x}\left(\mathrm{C}_{2} \mathrm{~B}_{10} \mathrm{H}_{12}\right)\right]$, new unoccupied states appear in the gap at $3.5 \mathrm{eV}$ above the Fermi level. As the $\mathrm{Na}$ doping is increased, the binding energy of this new density of states decreases, i.e., shifts towards the Fermi level, and the intensity increases. At a $\mathrm{Na}$ concentration of $x=2.5$, the binding energy of these states decreases to a value of $3.10 \mathrm{eV}$ above $E_{F} \cdot{ }^{10}$ As the Na doping level is increased beyond $x=3.5$, the states continue to broaden and to shift to lower energies. At approximately $x=5$, a well defined density of states is established at the Fermi level. We postulate that with sufficient doping the Na-orthocarborane film goes through a nonmetal to metal phase transition.

The origin of these Na-induced states may be due to hybridization of the $\mathrm{Na} 3 s$ valence electron with the unoccupied $s$ (and $p$ ) orbitals protruding from the orthocarborane cluster. Other possibilities include the substitution of ex- opolyhedral hydrogen with sodium, or the formation of bridge bonds between neighboring clusters by the sodium. Regardless of its origin, this Na-induced density of states resembles an upper Hubbard band. ${ }^{40-42}$ The shift in the density of unoccupied states towards the Fermi level with increased $\mathrm{Na}$ doping resembles the results for metal-insulator transitions which are based on the infinite dimensional Hubbard model. ${ }^{41,42}$

$\mathrm{Na}$ doping also introduces new occupied states into the gap above the HOMO, as seen in Fig. 3. The intensity of these two Na-induced bands increases with increasing $\mathrm{Na}$ concentrations until saturation at approximately 3.5 sodium atoms per orthocarborane cluster. This result demonstrates that metal doping of an icosahedral network introduces new states below the conduction band minimum (CBM).

A schematic of the energy bands of the Na-doped orthocarborane matrix is displayed in Fig. 2(b). The position of the Na-induced unoccupied states just above the Fermi level in Fig. 2(b) defines the CBM of the matrix film. The proximity of the CBM to the Fermi level defines the Na-doped molecular matrix as an $n$-type material. The significance of this with regards to the Ni-doped boron-carbon alloy films will be discussed in the following section.

It is useful to compare the energy bands of the Na-doped orthocarborane matrix with those of the theoretical energy bands of $\beta$-rhombohedral boron, which also has an icosahedral network structure. ${ }^{43}$ A schematic of the energy bands of $\beta$-rhombohedral boron is displayed in Fig. 2(c). The valence band of this material is split into two partially filled subbands VB1 and VB2. The splitting is attributed to Jahn-Teller distortions of the boron icosahedra. ${ }^{44}$ The similarity between the valence band structure of $\beta$-rhombohedral with that of the Na-doped orthocarborane matrix in Fig. 2(b) is quite remarkable. Based on this comparison, we argue that the $\mathrm{Na}-$ doped orthocarborane matrix emulates boron-rich and boron-carbon materials with icosahedral structure. This further validates the comparison of the electronic properties of the Na-doped orthocarborane matrix films with the Ni-doped boron-carbon alloy films in order to understand the role of Ni doping.

\section{Comparison of the electronic structure of Na-doped molecular matrix films with Ni-doped boron-carbon alloy films}

Valuable comparisons can be made between the electronic properties of the Ni-doped boron-carbon alloy films and the electronic structure of the Na-doped orthocarborane molecular matrix films. Both of these systems are composed of icosahedral boron cages, where the boron cages are covalently connected either directly or via intermediate isolated atoms or small clusters of $\mathrm{Ni}$ or $\mathrm{Na}$. Both of these materials are transformed from $p$-type materials to $n$-type with the inclusion of metal dopants.

Using the proposed electronic structure of boron-rich and boron carbide materials, we can describe the transformation of the $p$-type $\mathrm{B}_{5} \mathrm{C}$ alloy to and $n$-type material with $\mathrm{Ni}$ doping by treating the Ni atoms as donors. First, the behavior of 
the undoped material is attributed to the effects of JahnTeller distortions of the $B$ icosahedra, which results in splitting of the uppermost valence band. ${ }^{28}$ Since the split-off bands are not completely filled, they will act as acceptor states. Therefore, in order to create an $n$-type material it is necessary to overcompensate these split-off bands. The most obvious way of achieving this is to introduce donor states into the gap such that the Fermi level is shifted up towards the conduction band minimum [see Fig. 2(a)]. This is consistent with the rectifying behavior with reverse bias observed in Figs. 1(b) and 1(c) for the diodes constructed with the Ni-doped boron-carbon alloy films.

This description is supported by the spectroscopic data obtained for Na doping of the orthocarborane molecular matrix films. The interaction of the $\mathrm{Na}$ atoms with the molecular icosahedra results in charge transfer to the icosahedra which is manifested by the appearance of two new bands above the HOMO in Fig. 3. Like $\beta$-rhombohedral boron, the formation of two bands rather than one band with $\mathrm{Na}$ doping may be a consequence of Jahn-Teller distortions. This result is analogous to charge transfer in the Ni-doped boron-carbon alloy films. In addition, the large number of $\mathrm{Na}$ atoms per orthocarborane cluster $(x=3.5)$ is also consistent with the Ni doping of the alloy films.

$\mathrm{Ni}$ has a valency of two. If we make the assumption that approximately two valence electrons per $\mathrm{Ni}$ atom are donated to the boron icosahedral network, this would argue that we would need approximately two $\mathrm{Na}$ atoms to every $\mathrm{Ni}$ atom to achieve an equivalent level of charge transfer to a boron icosahedron. While this is speculative, it is consistent with the spectroscopy data in Fig. 3 of the Na-doped orthocarborane matrix films.

Concomitant with the introduction of new occupied states with $\mathrm{Na}$ doping is the introduction of new unoccupied states below the LUMO (see Fig. 3). This establishes the location of the Fermi level just below the conduction band minimum and thereby identifies the doped molecular matrix film as $n$-type. Again, this is consistent with the Ni doping of the boron-carbon alloy films.

Based on these comparisons of the Ni-doped boroncarbon alloys films with the Na-doped orthocarborane molecular matrix films, we have concluded that the role of $\mathrm{Ni}$ doping is to donate charge to the boron-carbon icosahedral network and consequently introduce new states into the gap. The introduction of these states into the gap is consistent with the tunnel diode behavior in Fig. 1(c).

The undoped molecular matrix films are also useful towards understanding the development of the conduction and valence band edges in the formation of the boron-carbon alloy films. The decomposition of orthocarborane with exposure to synchrotron radiation in Fig. 4 is accompanied by a decrease in binding energy of the residual molecular orbital features. This decrease in the binding energies of the photoemission features is a consequence of the gradual transition towards the formation of the boron-carbon valence and conduction bands from the orthocarborane molecular orbitals. ${ }^{45}$ The heterogeneous intermediate phase, made of a variety of

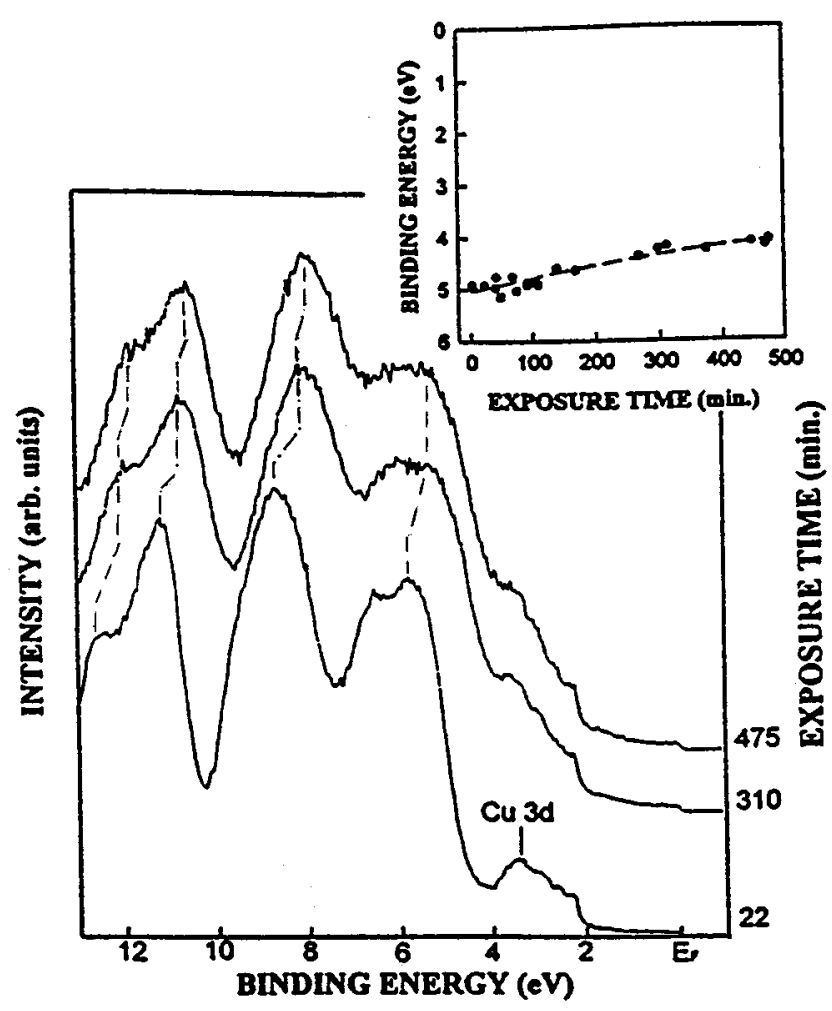

FIG. 4. Photoemission spectra of a molecular layer of orthocarborane on $\mathrm{Cu}(100)$ at $180 \mathrm{~K}$. The photon energy used was $25 \mathrm{eV}$. All photoelectrons were collected normal to the surface. Note the binding energy shifts and the broadening of the photoemission features with increased exposure to synchrotron light. The inset shows the binding energy shift of the highest occupied molecular orbital of orthocarborane as the valence band edge is established with the formation of boron-carbon.

orthocarborane fragments, has an electronic structure between that observed for molecularly condensed orthocarborane and the electronic structure anticipated for the rhombohedral boron-carbon alloy (based on the $\mathrm{B}_{12}$ icosahedral "'building block'), as seen in Fig. 5. This is clearly seen in the binding energy shift of the valence band edge established from the HOMO of orthocarborane (or $6 b_{2}$ ) with synchrotron radiation exposure, as seen in the inset to Fig. 4.

\section{SUMMARY}

We have demonstrated that molecular matrix films of cluster molecules are not only excellent source compounds for the fabrication of boron-rich semiconductor materials, but also furnish a simple electronic structure that can provide insight into the electronic structure and chemistry of solid semiconductor materials. The charge transfer between the $\mathrm{Na}$ atoms and the orthocarborane molecular clusters is analogous to the overcompensation necessary to transform the $p$-type $\mathrm{B}_{5} \mathrm{C}$ alloy films to $n$-type with nickel doping. In addition, the $\mathrm{Na}$-induced gap states provide an explanation for the tunnel diode behavior observed for the $\mathrm{B}_{5} \mathrm{C}$ alloy films with high Ni doping. 


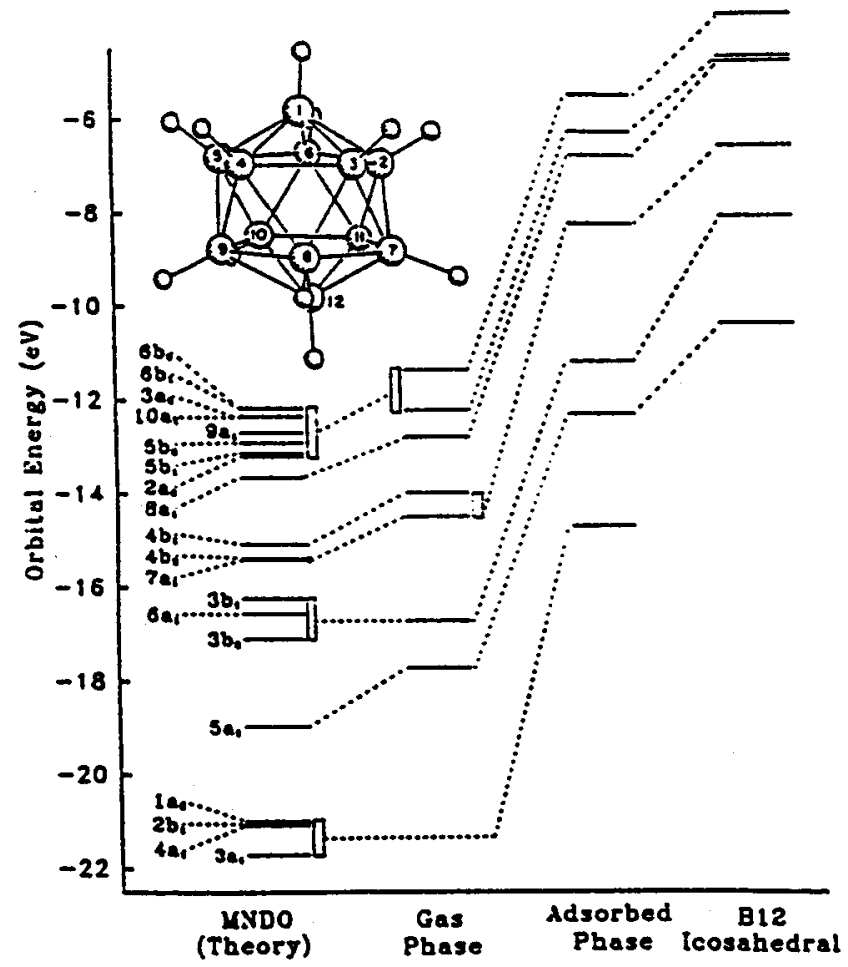

FIG. 5. A comparison of the molecular orbitals of orthocarborane as derived from semiempirical MNDO calculations (see Refs. 27 and 46), gas phase photoemission (see Ref. 47), from photoemission spectra of a molecular layer of orthocarborane adsorbed on $\mathrm{Cu}(100)$ (see Refs. 27 and 45), and for a $B_{12}$ icosahedra (see Ref. 48). The inset is a schematic representation of closo-1,2-dicarbadodecaborane. The 1,2 atoms are carbon and the 3-12 atoms are boron, and the unnumbered sites are hydrogen atoms.

\section{ACKNOWLEDGMENTS}

This work was supported by the AFOSR through Grant No. F49620-94-1-0433, the W. M. Keck Center for Molecular Electronics, and the Center for Materials Research and Analysis.

${ }^{1}$ D. Byun, B. R. Spady, N. J. Ianno, and P. A. Dowben, Nanostruct. Mater. 5, 465 (1995).

${ }^{2}$ S.-D. Hwang, D. Byun, N. J. Ianno, P. A. Dowben, and H. R. Kim, Appl. Phys. Lett. 68, 1495 (1996).

${ }^{3}$ S.-D. Hwang, N. B. Remmes, P. A. Dowben, and D. N. Mcllroy, J. Vac. Sci. Technol. B 14, 2957 (1996).

${ }^{4}$ S. Lee, J. Mazurowski, G. Ramseyer, and P. A. Dowben, J. Appl. Phys. 72, 4925 (1992).

${ }^{5}$ S. Lee, T. Ton, D. Zych, and P. A. Dowben, Mater. Res. Soc. Symp. Proc. 283, 483 (1993).

${ }^{6}$ S. Lee and P. A. Dowben, Appl. Phys. A 58, 223 (1994).

${ }^{7}$ D. Byun, S.-D. Hwang, P. A. Dowben, F. K. Perkins, F. Filips, and N. J. Ianno, Appl. Phys. Lett, 64, 1968 (1994).

${ }^{8}$ D. N. Mcllroy, J. Zhang, P. A. Dowben, P. Xu, and D. Heskett, Surf. Sci. 328, 47 (1995).

${ }^{9}$ D. N. Mcllroy, J. Zhang, P. A. Dowben, and D. Heskett, Mater. Sci. Eng. A 217/218, 64 (1996).

${ }^{10}$ D. N. McIlroy, C. Waldfried, P. A. Dowben, and D. Heskett, Chem. Phys. Lett. 264, 168 (1997).

${ }^{11}$ R. J. Cava, B. Batlogg, J. J. Krajewski, W. F. Peck, T. Siegrist, R. M.
Fleming, S. Carter, H. Takagi, R. J. Felder, R. B. van Dover, and L. W. Rupp, Physica C 226, 170 (1994).

${ }^{12}$ R. J. Cava, H. Takagi, H. W. Zandbergen, J. J. Krajewski, W. F. Peck, T. Siegrist, B. Batlogg, R. B. van Dover, R. J. Felder, K. Mizuhashi, J. O. Lee, H. Eisaki, and S. Uchida, Nature 367, 252 (1994).

${ }^{13}$ T. Siegrist, H. W. Zandbergen, R. J. Cava, J. J. Krajewski, and W. F. Peck, Nature 367, 254 (1994).

${ }^{14}$ K. Widder, D. Berner, A. Zibold, H. P. Geserich, M. Knupper, M. Kielwein, M. Buchgeister, and J. Fink, Europhys. Lett. 30, 55 (1995).

${ }^{15}$ R. Nagarajan, C. Mazumdar, Z. Hossain, S. K. Dhar, K. V. Gopalakrishnan, L. C. Gupta, C. Godart, B. D. Padalia, and R. Vijayaraghavan, Phys. Rev. Lett. 72, 274 (1994).

${ }^{16}$ N. Kobayashi, Y. Kumashiro, P. Revesz, J. Li, and J. W. Mayer, Appl. Phys. Lett. 54, 1914 (1989).

${ }^{17}$ N. Kobayashi, Y. Kumashiro, P. Revesz, J. Li, and J. W. Mayer, Mater. Res. Soc. Symp. Proc. 162, 595 (1990).

${ }^{18}$ K. P. Callahan and M. F. Hawthorne, Adv. Organomet. Chem. 14, 145 (1976).

${ }^{19}$ M. F. Hawthorne, D. C. Young, T. D. Andrews, D. V. Howe, R. L. Pilings, A. D. Pitts, M. Reintjes, L. F. Warren, and P. A. Wegner, J. Am. Chem. Soc. 90, 879 (1968).

${ }^{20}$ L. F. Warren and M. F. Hawthorne, J. Am. Chem. Soc. 90, 4823 (1969).

${ }^{21}$ L. F. Warren and M. F. Hawthorne, J. Am. Chem. Soc. 92, 1157 (1970).

${ }^{22}$ Y.-G. Kim, D. Byun, C. Hutchings, P. A. Dowben, H. Hejase, and K. Schroeder, J. Appl. Phys. 70, 6062 (1991).

${ }^{23}$ G. T. Stauf, D. C. Driscoll, P. A. Dowben, S. Barfuss, and M. Grade, Thin Solid Films 153, 421 (1987).

${ }^{24}$ G. T. Stauf and P. A. Dowben, Thin Solid Films 156, L31 (1988).

${ }^{25}$ N. M. Boag and P. A. Dowben, Metallized Plastics 4: Fundamental and Applied Aspects, edited by K. L. Mittal (Plenum, New York, 1996).

${ }^{26}$ D. Zych, A. Patwa, S. S. Kher, J. T. Spencer, J. Kushneir, A. J. Goodby, N. M. Boag, and P. A. Dowben, J. Appl. Phys. 76, 3684 (1994).

${ }^{27}$ H. Zeng, D. Byun, J. Zhang, G. Vidali, M. Onellion, and P. A. Dowben, Surf. Sci. 313, 239 (1994).

${ }^{28}$ U. Kuhlmann, H. Werheit, T. Dose, and T. Lundstr $\measuredangle m$, J. Alloys Compd. 186, 187 (1992).

${ }^{29} \mathrm{H}$. Werheit, K. de Groot, W. Malkemper, and T. Lundstrøm, J. LessCommon Met. 82, 163 (1981).

${ }^{30}$ U. Kuhlmann, H. Wertheit, J. Pelloth, W. Keune, and T. Lundstrøm, Phys. Status Solidi B 187, 43 (1995).

${ }^{31}$ A. G. Chynoweth, W. L. Feldmann, and R. A. Logan, Phys. Rev. 121, 684 (1961).

${ }^{32}$ R. S. Claassen, J. Appl. Phys. 32, 2372 (1961).

${ }^{33}$ A. S. Epstein and J. F. Caldwell, J. Appl. Phys. 35, 3050 (1964).

${ }^{34}$ E. O. Kane, Phys. Chem. Solids 2, 181 (1960).

${ }^{35}$ E. O. Kane, J. Appl. Phys. 32, 83 (1961).

${ }^{36}$ J. Karlovsky, Solid-State Electron. 10, 1109 (1967).

${ }^{37}$ R. A. Logan and A. G. Chynoweth, Phys. Rev. 131, 89 (1963).

${ }^{38}$ D. Meyerhofer, G. A. Brown, and H. S. Sommers, Jr., Phys. Rev. 126, 1329 (1962).

${ }^{39}$ R. M. Minton and R. Glicksman, Solid-State Electron. 7, 491 (1964).

${ }^{40}$ H. Eskes, M. B. J. Meinders, and G. A. Sawatzky, Phys. Rev. Lett. 67, 1035 (1991).

${ }^{41}$ S. Wermbter and G. Czycholl, J. Phys., Condens. Matter 6, 5439 (1994).

${ }^{42}$ X. Y. Zhang, M. J. Rozenberg, and G. Kotliar, Phys. Rev. Lett. 70, 1666 (1993).

${ }^{43}$ H. Werheit, U. Kuhlmann, M. Laux, and T. Lundstr Solidi B 179, 489 (1993).

${ }^{44}$ R. Franz and H. Werheit, Europhys. Lett. 9, 145 (1989).

${ }^{45}$ D. Byun, S.-D. Hwang, J. Zhang, H. Zeng, F. K. Perkins, G. Vidali, and P. A. Dowben, Jpn. J. Appl. Phys. 34, L941 (1995).

${ }^{46}$ A. P. Hitchcock, A. T. Wen, S. Lee, J. A. Glass, Jr., J. T. Spencer, and P. A. Dowben, J. Phys. Chem. 97, 8171 (1993).

${ }^{47}$ P. Brint, B. Sangchakr, M. McGrath, T. R. Spalding, and R. J. Suffold, Inorg. Chem. 29, 47 (1990).

${ }^{48}$ D. W. Bullett, AIP Conf. Proc. 140, 249 (1986). 